\title{
EL ROMANCERO EN QUIÑONES DE BENAVENTE
}

Uno de los recursos cómicos preferidos por el entremesista Luis Quiñones de Benavente es el de intercalar, entre los propios, versos ajenos, sobre todo de romances ${ }^{1}$. Estas citas, arrancadas de su contexto y encajadas a la fuerza en otro nuevo, provocan la risa por lo incongruente o por lo inesperadamente certero. Pero es una técnica que requiere la colaboración del público. Si las citas no se reconocieran como tales, muchas de ellas, lejos de ser graciosas, no tendrían siquiera sentido. Precisamente por estar hoy olvidados muchos romances que en otros tiempos cantaba todo el mundo, algunos pasajes de piezas jocosas resultan casi ininteligibles para el lector moderno. Desde luego, no sería así cuando se compusieron. En los teatros del Siglo de Oro, donde había que granjearse el favor del noble en su aposento lo mismo que el del mosquetero en el patio, el poeta se veía obligado a renunciar a juegos de ingenio que no estuvieran al alcance de todos. Las alusiones recónditas aburren a quien no las entiende, y el mosquetero aburrido no tardaba en silbar y armar escándalo. En cambio, una alusión entendida produce una satisfacción muy especial, la de sentirse inteligente y tal vez un poquito superior al vecino que no ha caído en la cuenta. Esta satisfacción se traduce en una disposición más abierta para celebrar los chistes y dar los "vítores" tan deseados por cómicos y poetas. Los romances citados tenían que ser fáciles de identificar, y figurarían, por consiguiente, entre los más divulgados de la época. Así, el estudio de estas citas, además de ilustrar un aspecto del estilo de Quiñones, nos ofrece la posibilidad de establecer un breve índice de algunas de las poesías mejor conocidas en sus tiempos.

Antes de emprender la identificación de estos préstamos ${ }^{2}$, con-

1 De la misma manera se utilizan a veces títulos de comedias, cantos populares, refranes o frases hechas. El presente estudio se limita a los romances; espero tratar algún día del empleo de otros materiales folklóricos.

2 La primera edición moderna de las obras del entremesista llama la atención sobre ellos pero no siempre los distingue tipográficamente, por ser "sobrado conocidos" (Colección de piezas dramáticas, entremeses, loas y jácaras. .., ed. CAYETano Rosell, Madrid, $1872-74$, t. 1, p. 453). Que no lo son todos, lo demuestran las notas a "en virtud del azadón" (p. 456) y a "quien sus rayos la dio el Sol" (p. 468). Iulio Monreal, "Rebusca literaria sobre los entremeses de Be- 
vendrá examinar los procedimientos mediante los cuales engasta Quiñones en sus versos los elementos extraños, y la manera como explota sus posibilidades cómicas.

El método más empleado por nuestro autor para engarzar en su texto los versos ajenos consiste en emplear la rima de estos versos en los que los preceden. Por lo común se sirve de redondillas o quintillas $^{3}$, dejando los versos de la cita -que casi siempre son dos-para el remate de la estrofa. En la Loa que representó Antonio de Prado ${ }^{4}$ hay 24 redondillas (divididas en dos series), cada una de las cuales contiene, en sus versos $3-4$, una de esas citas. Después de dos o tres coplas, esta alternancia regular ha quedado manifiesta; se añade un placer anticipatorio al gusto del reconocimiento: lo inesperado se hace esperado. Pero antes de que el juego llegue a la monotonía, el poeta lo interrumpe con un abrupto cambio métrico, para reanudarlo después con mayor regocijo. En la Loa Fernández, logra efectos más sutiles mediante un esquema poliestrófico. Cada interlocutor empieza con una tirada de dos a diez versos de pie de romance ${ }^{5}$ y luego dice los dos (o tres) primeros versos de una redondilla (o quintilla), y el coro lo interrumpe cantando los dos versos de algún romance conocido y completando así la copla. Tenemos aquí el mismo efecto de anticipación que se señaló en la Loa Prado, pero con un ritmo fluctuante, porque varían en extensión las tiradas de romance que preceden a las coplas rimadas. Un elemento nuevo es la distribución del diálogo: aunque íntimamente ligadas al contexto por la rima, en la representación de la pieza las citas funcionan como interrupciones; y las acotaciones (cantan) nos hacen saber que las citas de romances, además de textuales, eran musicales. Lo mismo se haría en otros casos, lo cual podría explicar la gran popularidad de esta técnica. En Don Gaiferos ${ }^{6}$ aparece (en cuatro casos) otro refinamien-

navente" (reimpreso en Colección. ., t. 2, pp. 372-375), añade cuatro a los dos romances identificados por Rosell; Cotarelo (NBAE, t. 18, p. $5^{17}$ ) señala dos más.

${ }^{3}$ Estrofas raras en Quiñones de Benavente; las hallamos casi exclusivamente en situaciones como las analizadas aquí o en otras análogas, donde quiere crear efectos cómicos por medio de la métrica.

${ }^{4} N B A E$, t. 18 , pp. $5^{16-517}$. Cito siempre por esta edición. Abreviaré algunos títulos: éste se citará en adelante como Loa Prado; Loa con que empezó Tomás Fernández en la Corte (Loa Fernández); Loa con que empezó en la Corte Roque de Figueroa (Loa prim. Figueroa); Loa segunda, con que volvió Roque de Figueroa a empezar en Madrid (Loa seg. Figueroa); Loa con que empezaron Rueda y Ascanio (Loa Rueda). EI mayor número de citas se halla en Loa Prado (23), Los planetas (17), Loa Fernández (12) y Don Gaiferos (12).

` La asonancia, mantenida siempre en $a-o$, da unidad a la escena.

- Comprende este estudio todas las obras adscritas a Quiñones de Benavente en la ed. de Cotarelo (NBAE, t. 18), donde hay algunas de atribución dudosa, como ésta de Don Gaiferos. Lo que digo de ella, por consiguiente, no vale sino como un dato más para la popularidad de los romances citados y para la técnica de citar romances en general. 
to: acaba una quintilla con los dos primeros versos de algún romance, y la siguiente con los versos tercero y cuarto del mismo.

En los pocos casos en que se citan o parodian más de dos versos, el poeta los añade a una tirada de romance con la misma asonancia. En La puente segoviana $I$ y $I I$ se interrumpe la tirada cada cuatro versos con una seguidilla, sin distinción entre lo citado y lo nuevo.

De menor interés son los lugares en que, pidiendo la acción que un personaje cante algo, se canta un romance sin ninguna trabazón rímica con lo que precede. Esto es raro, y donde más se emplea -en Los órganos y sacristanes-, a cada trozo cantado sigue un comentario sobre la letra.

Los romances recordados por Quiñones pertenecen en su mayoría al Romancero Nuevo. Aunque los versos citados suelen ser los iniciales, no faltan casos en que se citan, además, versos interiores. Estos romances debían de ser archiconocidos. Unas veces el poeta reproduce los versos exactamente como los traen los romanceros; otras, introduce ligeras variantes. Es muy común que haga cambios deliberados para adaptarlos a la situación. Veamos un ejemplo ( Loa Fernández, p. 559 b): Isabel, especializada en los papeles de tercera dama en la compañía de Fernández, se queja así de las actrices que desempeñaban esos mismos papeles en compañías rivales:

$$
\begin{gathered}
\text { Iss.-_Qué sentiré oyendo esto, } \\
\text { yo, que las terceras hago, } \\
\text { cuando Antonia es un portento } \\
\text { y Josefa es un milagro? } \\
\text { A vuestros pies humillada } \\
\text { me acojo, porque sitiada } \\
\text { de las dos, si lucir quiero... } \\
\text { Todos (cantan).- } \\
\text { de Antonia me cerca Duero, } \\
\text { de estotra Peña Tajada. }
\end{gathered}
$$

Pero aun cuando las palabras sean las tradicionales, pueden adquirir nuevos matices al pasar de su contexto original a otro. Los silbos campestres que se oyen en el poema de Góngora (ed. Foulché-Delbosc, t. 2, p. 122):

$$
\begin{aligned}
& \text { ¡Quántos siluos, quántas voces } \\
& \text { la naua oió de Zuheros, } \\
& \text { sentidas bien de sus valles, } \\
& \text { guardadas mal de sus Echos! } \\
& \text { Vaqueros las dan, buscando } \\
& \text { la hermosa por lo menos, } \\
& \text { cerrera, luciente hija } \\
& \text { de el toro que pisa el cielo, }
\end{aligned}
$$

apenas se reconocen en el estrépito teatral evocado por la Autora en la Loa Prado (p. $5^{1} 7^{b}$ ): 
Pues que mi piedad conoces, discreta gente de a pie, silba, que yo sufriré cuántos silbos, cuántas voces.

¿Cómo elige el poeta sus citas? Las mejores vienen a pelo sin la menor alteración textual, si bien con un trastorno conceptual que haría las delicias del mosquetero. Entre las más ingeniosas están las que llevan el nombre del actor que ha de decirlas (o a cuya intención se han de decir), además de algún equívoco. Así en la presentación de Bartolomé Romero, antes autor (jefe de compañía) y ahora simple compañero o actor (Loa Fernández, p. $559 b$ ):

$$
\begin{aligned}
& \text { Rom.- Siendo autor, pedí por muchos; } \\
& \text { hoy, sólo por mí, fiado } \\
& \text { en que algún favor tendrá } \\
& \text { quien le alcanzó para tantos; } \\
& \text { si no es que por holgazán, } \\
& \text { de autor vuelto en compañero... } \\
& \text { Todos (cantan).- } \\
& \text { En figura de Romero, } \\
& \text { no te conozca Galván. }
\end{aligned}
$$

Un poco más abajo (p. $5^{60 a}$ ), las bravatas del gracioso Bernardo de Medrano:

$$
\begin{gathered}
\text { BER.-Si ahora viniera a ser } \\
\text { gracioso de estos tablados, } \\
\text { venga uno y vengan ciento, } \\
\text { que confiado y gallardo, } \\
\text { para reparar sus furias. . } \\
\text { Todos (cantan).- Con los mejores de Asturias } \\
\text { sale de León Bernardo. }
\end{gathered}
$$

En la Loa Prado (p. $5^{17 a}$ ) calla modestamente Domingo Ochoa de Arroyo:

$$
\begin{gathered}
\text { ArRoyo-Yo callo el consejo mío, } \\
\text { que soy entre tantos mares } \\
\text { Manzanares, Manzanares, } \\
\text { arroyo aprendiz de río. }
\end{gathered}
$$

En otros casos la cita resulta lógica por la asociación de ideas, pero además graciosa por algún elemento incongruente. En la Loa Fernández, cuando se han presentado todos los individuos de la compañía - no sin cierta confusión-, se echa de menos al autor (p. $5^{60 a)}$ :

BER.-¿¿ónde al autor hallarán? Compañía, ¿dónde queda?

Todos (cantan).-Con la mucha polvareda, perdimos a don Beltrán. 


$$
\begin{gathered}
\left(\text { Representado }^{7}\right. \\
\text { BER.-Busquémosle en su posada, } \\
\text { que su presencia conviene. } \\
\text { Todos (cantan)-iHelo, helo por dó viene } \\
\text { el moro por la calzada! }
\end{gathered}
$$

Lógico -casi inevitable- es que la salida del personaje Venus vaya acompañada por las palabras "Sale la estrella de Venus" (Los planetas, p. $\left.5^{61} b\right)$, o que al presentarse el personaje alegórico La Verdad se le cante un verso en que figure su nombre (La Verdad, p. 572b).

Ciertos versos, a fuerza de repetirse, habían adquirido una función sintáctica, como la de empezar una narración:

$$
\begin{aligned}
& \text { Arg._... Cuente el caso... } \\
& \text { Cos.-Pues va de relación... } \\
& \text { Era de Julio la estación primera... } \\
& \text { Arz.-Es mentira, que a diez de Julio era }{ }^{8} \text {. }
\end{aligned}
$$

Algunos se habian popularizado tanto que llegaron a ser proverbiales; fueron recogidos en refraneros, y su uso en los entremeses ya no se diferencia del de otras frases hechas.

Hay citas que parecen provocadas por la rima; cf. Loa Fernández, p. $559 b$ :

$$
\begin{gathered}
\text { Loв.-Mas si me paso de calles } \\
\text { en los bailes y entremeses... } \\
\text { Tobos (cantan)-Mala la hubisteis, franceses, } \\
\text { la caza de Roncesvalles. }
\end{gathered}
$$

$\mathrm{Y}$, por fin, las hay deliberadamente incongruentes, como en la entrevista amorosa de Marte y Venus (Los planetas, p. $5^{61} b$ ):

$$
\begin{aligned}
& \text { Marte-Ya tenemos claridad: } \\
& \text { ¿Qué hemos de hacer, Venus mía? } \\
& \text { Venus-Vámonos, dijo mi tía, } \\
& \text { a París, esa ciudad. }
\end{aligned}
$$

Tres obritas atribuidas a Quiñones de Benavente se valen de romances vulgarísimos de una manera completamente distinta. Los

'Quiere decir 'hablado' (no cantado).

${ }^{8}$ Las silvas podían servir para empezar una narración, pero no para continuarla. Sigue la escena:

$$
\begin{aligned}
& \text { Cos.-iAy, qué deshonra! ¿A mí mentís? } \\
& \text { Alg.- Acabe. } \\
& \text { Arz.-Yo haré la relación, que ella no sabe } \\
& \quad \text { de la misa la media: } \\
& \quad \text { póngome de romance de comedia. }
\end{aligned}
$$

Y continúa en romance ( $E l$ avantal, pp. $645^{-646)}$ ). 
zaparrastrones y Bras y Menga $^{9}$ parodian los romances pastoriles. En la primera, después de cantar los músicos (p. $8_{3} 8 a$ ):

Ya murieron Menga y Bras, aquel bello par de orates, tan iguales en morirse como locos en amarse,

resucitan Bras y Menga para negar enfáticamente su muerte por amores. Pregunta Bras (p. $8_{9} 8 b$ ):

¿Luego no os moristeis, Menga, por lo que dice el romance?

y tras una animada discusión, Menga resuelve cambiar de conducta para que no se hagan tantas canciones a su propósito (p. 839a):

De hoy más seré una santita, conque no se oirá en el valle para Menga tanta letra, para Bras tanto romance.

Bras y Menga empieza con la misma copla, pero esta vez los amantes insisten en que sí murieron como lo dicen los poetas, y citan el precedente de los amantes de Teruel. Menga volverá a la vida (p. 839b),

...mas con condición que más mi historia no canten.

El negrito hablador está dedicado principalmente a parodiar, en la lengua convencional de los negros de teatro, tres romances: "Sin color anda la niña", "Afuera, afuera, afuera”, y "Ya está metido en la trena”. Citaré un trozo típico (p. 6o6a):

ANG.-Cantadle, pues no nos deja, afuera, afuera, afuera, aparta, aparta, aparta.

Negro-"Entra el vareroso Musa, cuadriniero de unaz cañaz". ¿Zabe qué quiere desir? Que tan vareroso era esta beyaca de Musa, que cuando entlaba en las fiestaz, atropeyaba los niñoz y a tora gente prebeya. Y así dise cuando zale, porque narie tenga queja:

${ }^{8}$ Estas dos obras se parecen tanto por su asunto, que una, al menos, debe ser apócrifa. Para el tema de Bras y Menga véase Primavera y flor de los mejores romances (Madrid, I62I), ed. J. F. Montesinos, Valencia, 1954, Pp. 269-270. 
"Afuera, afuera, que salgo"; y polque mejor lo advielta, dise luego: "Ampalta, ampalta" y anvisa de ros manelas que entla el vareroso Musa.

Parodia también, pero no de un romance determinado, sino de los romances de ciegos en general, es el comienzo de la Loa Rueda (p. $575^{b)}$ :

\author{
¡Ah, galanes! Obra nueva. \\ ¿Quién me la compra, soldados? \\ Que trata de lo que anoche \\ sucedió a Rueda y Ascanio; \\ cómo estando en su sosiego \\ vino el enemigo malo \\ y los revistió de autores \\ sin saber cómo ni cuándo. \\ Es historia verdadera, \\ con un villancico al cabo \\ en que declara las deudas \\ que hay de sólo imaginallo ${ }^{10}$.
}

\title{
I. Romances viejos
}

"Asentado está Gaiferos / en el palacio real” (WH, 173; D, $377)^{11}$. En el entremés Don Gaiferos leemos: "Caballero, si a Francia ides, / por Gaiferos preguntad" (p. 612b), y un poco más abajo: "y decid que la su esposa / se lo envía a encomendar". En la Loa Fernández: "De noche por los caminos, / de día por los jarales" (p. 559a), versos parodiados en Los zaparrastrones: "De día con las comedias, / de noche en particulares" (p. $839 a)^{12}$.

${ }^{10}$ Cf. Quevedo, Obras en verso, ed. L. Astrana Marín, Madrid, 1943, p. 269a: "¿Quién me compra, caballeros, / que es obra famosa y nueva: / un calendario del año / que tienen las faltriqueras?"

11 WH: F. J. Wolf y C. Hofmann (eds.), Primavera y flor de romances, en M. Menéndez Pelayo, Antología de poetas liricos castellanos, t. 8, Madrid, 1945; D: Agustín Durán (ed.), Romancero general, $B A E$, ts. 10 y 16 (el número es el del romance). Para más datos bibliográficos remito a estas dos colecciones. Señalo citas de los mismos romances en otros autores cuando han llegado a mi atención, pero no pretendo hacer un estudio completo de ninguno de ellos. Desde luego, las técnicas descritas aquí no son exclusivas de nuestro autor, y un análisis detenido de todas las obras jocosas de la época daría sin duda un índice de romances mucho más nutrido que el que ofrezco aquí. - Para Lope se ha hecho un estudio parcial, si bien desde otra perspectiva (JеRоme A. Moore, The Romancero in the chronicle-legend plays of Lope de Vega, Philadelphia, 1940). Diez romances del presente catálogo figuran allí, más alguno citado de pasada.

12 Todos conocen este romance por la cita del Quijote, II, 26: "De noche por los caminos, / de día por los jarales" figura también en "Vámonos, dijo, mi tío" (infra). 
"Helo, helo por dó viene / el moro por la calzada" (Cid, WH, 55; $\mathrm{D}, 858$ ). Este comienzo se cita sin variación en Don Gaiferos (p. 612b) y en la Loa Fernández (p. $5^{60 a}$ ), como en innumerables obras de la época. "Helo, helo, por dó viene / el portal de los Mauleros" ( $E l$ casamiento de la Calle Mayor, p. 557a) podría derivarse del mismo romance o de "Helo, helo por dó viene / el infante vengador" (WH, 150; D, 294).

"La mañana de Sant Joan, / al tiempo que alboreaba" (fronterizo, WH, 75; cf. D, 8o y 1043). En Don Gaiferos (p. 612b: "de San Juan").

“'Mala la vistes, franceses, / la caza de Roncesvalles!” (WH, 186; D, 402). Citado en la Loa Fernández (p. 559 b: "hubisteis") ${ }^{13}$.

"Media noche era por filo, / los gallos querían cantar" (Conde Claros, WH, 190; D, 362). Adaptando los versos 11-12 al personaje (el planeta Marte) escribe Quiñones: "Salto da del quinto cielo, / que parece un gavilán" (Los planetas, p. $5^{61} b$ ). Sustituyendo yerros por bailes, porque lo pide la situación, en la Loa Prado: “Que los bailes por amores / dignos son de perdonar" (p. $5^{17} a$ ). Alude en varios lugares a este famosísimo pasaje: "Perdonad yerros y faltas; / que los hechos por amores / perdón merecido alcanzan" (Loa prim. Figueroa, p. 533a); "Que siempre están disculpados / los que yerran por amor" (Turrada, p. 537a); "Perdóname, y advierte / que son yerros de amor" (El doctor y el enfermo, p. 6o4b). Tal vez se inspiran en otra versión los versos "Media noche era por filo; / la Luna daba en la calle" (Los planetas, p. $\left.5^{61} b\right)^{14}$.

"Morir vos queredes, padre, / San Miguel vos haya el alma" (Cid, WH, 36; D, 763 ). Quiñones cita tres veces la queja de doña Urraca, siempre con alguna deformación determinada por el contexto: "A las feas, por dinero, / a las hermosas, de gracia" (La capeadora I, p. 55ob); "De Antonia me cerca Duero, / de estotra, Peña Tajada" (Loa Fernández, p. $559 b$ ); "Quien te la quitare, Osuna, / la mi maldición le caya" (Loa Fernández, p. $559 a)^{15}$.

"¡Oh, Belerma! ¡Oh, Belerma! / por mi mal fuiste engendrada"

${ }^{13}$ La lección hubisteis es común en recuerdos de este romance, citado también en el Quijote, II, 9. Sobre su divulgación véase R. MEnÉndez Pidal, Flor nueva de romances viejos, Madrid, 1928, p. 114, y León Medina, "Frases literarias afortunadas", $R H i, 18$ (1908), pp. $184-185$.

${ }^{14}$ Los dos versos iniciales están también en WH, 174 (Gaiferos). Para las alusiones de Lope al romance del Conde Claros (otra cita en el Quijoter, II, 9), véase R. Menéndez Pidal, "Lope de Vega. El arte nuevo y la nueva biografía”, RFE, 22 (1935), pp. 345-346, y Menéndez Pelayo en la ed. de Lope, Acad, t. 2, p. lxxviii; para Salas, G. LAGrone, "Some poetic favorites of Salas Barbadillo", HR, 13 (1945), p. 39. E. H. TEMPLIN, The exculpation of "yerros por amores" in the Spanish "comedia", Berkeley, 1933, analiza la Weltanschauung cristalizada en estos famosos versos.

${ }^{15}$ Sobre su popularidad, véase MEnÉndez Pidal, Flor nueva, p. 236. 
(Durandarte, WH, 181; D, 387). Se hicieron proverbiales los versos recordados por Quiñones: "Ojos que le vieron ir, / no le verán más en Francia" (Loa Fernández, p. $561 a$; también en Los escuderos y el lacayo, p. 814a: "las... las") ${ }^{16}$.

"Rey don Sancho, rey don Sancho, / no digas que no te aviso" (Cid, WH, 45 y 44; D, 777). Citado en la Loa Prado (p. $5^{17}$ a: "dirás") y parodiado en la Jácara... de Romero (p. $55^{8 a}$ ):

Jacarita, jacarita, no digas que no te aviso, que del Real de donde cobran una moza había salido ${ }^{17}$.

"Vámonos, dijo, mi tío, / a París esa ciudad" (Gaiferos, WH, 172; $\mathrm{D}, 375)$. Con una variante pedida por la rima, en Los planetas (p. 561b: "tía"), y parodiado en versos de cabo roto: "Vámonos, dijo mi ti-, / a dormir al vistua-", en El sueño (p. 644a). Variados, para adaptarlos a la situación: "En figura de Romero, / no me conozca Galván" (Loa Fernández, p. 559 b) e igualmente en Loa seg. Figueroa (p. $546 a$ : "Romero... vos") $)^{18}$.

\section{Romances NuEvos ${ }^{19}$}

"Afuera, afuera, afuera, / aparta, aparta, aparta" (RG, 61; D, $88)^{20}$. Este famoso romance, probablemente obra de Lope, estaba divulgadísimo por entonces, y en particular su animado comienzo. Quiñones lo usa repetidamente para efectos escénicos (La puente segoviana $I$ y $I I$, pp. $533^{b}$ y $537 b$; Los planetas, p. $562 a ;$ La casa al revés, p. 82gab; Jácara... de Romero, p. 558a). También llegaron a ser proverbiales "No hay amigo para amigo; / las cañas se vuelven lanzas" (Loa Fernández, p. $559 \mathrm{~b}$ ). Hay un comentario burlesco al romance entero en El negrito hablador (p. 6o6ab).

"Al campo de Leganitos, / que en virtud del azadón"21. Los dos

${ }^{16}$ Cf. Menéndez Pidal, Flor nueva, p. 105.

${ }^{17}$ Otra parodia, entre muchas más, en el entremés de Quevedo Los refranes del viejo celoso (Obras en verso, p. 559 b): "Biexo clueco, biexo clueco, / no digas que no te abiso, / que de la seiba encantada / un máxico aia salido".

18 Véase Medina, $R H i$, 20 (1909), pp. 247-248. Correas da como proverbiales los cuatro versos que señalamos (Vocabulario, ed. Madrid, 1924, pp. 432 y 499).

${ }_{10}$ Por ser pocas, incluyo en esta sección citas de versos cultos que no son romances. En cambio, omito hasta una docena de letrillas de tipo popular recogidas en el Romancero general.

${ }_{20}$ RG: Romancero general, ed. A. González Palencia, Madrid, 1947. RG y $\mathrm{D}$ comprimen los dos primeros versos en uno. Sobre la atribución y difusión de este romance, cf. J. F. Montesinos, Estudios sobre Lope, México, 1951, p. 283 y nota; Medina, $R H i$, 20 (1909), pp. 250-251. Entre las infinitas citas de este romance recordemos la del Quijote, II, 12.

${ }^{21}$ Monreal, art. cit., p. 375, lo halló manuscrito en la Bibl. de Palacio, 
primeros versos se citan en Los planetas (p. $5^{61 b}$ ), y los cuatro primeros en Don Gaiferos (p. 612b).

"Al zurdillo de la costa / hoy otra vez le azotaron" (Cáncer)22. Se cantan los cuatro primeros versos de esta jácara en Los órganos y sacristanes (p. 637a).

"Antes que barbas tuviese, / Rey Alfonso, me juraste" (RG, $3^{87}$; D, 656). Sin alteración en la Loa Prado (p. $5^{17 a}$ ).

"Aprended, flores, de mí/lo que va de ayer a hoy" (letrilla glosada por Góngora, Lope y muchos otros ${ }^{23}$. Con sustitución de "flores" por "damas" se halla en la Loa Prado (p. $5^{16 b}$ ).

"Aquella Luna hermosa / que sus rayos le dio el Sol" (Álvaro de Luna, D, 998; de la Silva de varios romances). En Los planetas: "Aquella Luna hermosa / quien sus rayos la dio el Sol" (p. $\left.5^{61}\right)^{2+2}$.

"Ay, verdades, que en amor / siempre fuystes desdichadas" (Primavera y flor, ed. cit., pp. 137-140; D, 1557$)^{25}$. Quiñones cita el comienzo en la Loa Prado (p. $5^{17} b$ ) y parodia toda la cuarteta primera en la pieza alegórica $L a$ Verdad (p. $572 b$ ): “Ay, Verdad, que en el hablar / siempre fuiste desgraciada! / Buen ejemplo son las hembras, / pues de mentiras se pagan".

"Bien podéis, ojos, llorar, / no lo dejéis de vergüenza" (RG,

M-I62, fol. $49 \mathrm{v}^{\circ}$. El ms. 3700 de la B. N. M. lo atribuye a Quevedo; esta versión es, salvo unas cuantas variantes, la que se canta in extenso al final del anónimo Baile de Leganitos (NBAE, t. 18 , pp. $488-489$; de la $5^{\text {a }}$ parte de Comedias de diferentes autores, Barcelona ${ }_{1616)}$. El baile es escenificación del romance. LAGrone, op. cit., p. 44, considera el romance obra de Salas Barbadillo, de acuerdo con Astrana, ed. Quevedo, Obras en verso, p. $1366 a$.

${ }^{22}$ Gerónimo Cáncer, Obras varias, Madrid, $\mathbf{1 6}_{5^{1}}$, fol. $68 \mathrm{r}^{\mathbf{0}}$; también, anónimo, en Romances varios de diversos autores, Madrid, Pablo de Val, 1655, p. 125 (todos los romances que cito de esta colección, con excepción de la jácara de Quevedo "Ya está guardado en la trena", figuran asimismo en la ed. de 1640). Para versiones manuscritas, cf. JoHn M. Hill (ed.), Poesías germanescas, Bloomington, 1945 , p. 167 .

23 Góngora, ed. cit., t. 2, pp. 358-359 (“en mi”); Lope, La moza de cántaro, II, $A c a d N$, t. 13, p. 663b (“de mí). Otra cita, sólo de los dos primeros versos, en la Mogiganga del rey D. Rodrigo y la Caba, de Moreto, Valladolid, Alonso del Riego, s. a., p. 4, y en Autos sacramentales..., Madrid, Ma de Quiñones, 1655, fol. $92 \mathbf{v}^{\circ}$. En el romance "Guardainfante era, y ya estoy" (Romances varios, p. 256), donde se citan muchos versos de romances, leemos "que aprender podéis de mí / lo que va de ayer a hoy: / hoy risa del pueblo soy, / ayer fui todo su vicio". Véase Medina, RHi, 25 (1911), pp. 54-55, y Margit Frenk AlaTORRE, "Refranes cantados y cantares proverbializados", en este mismo volumen de la $N R F H$, p. 166.

${ }_{24}$ Así en la ed. príncipe (Iocoseria..., Madrid, Francisco García, 1645); Cotarelo adopta la enmienda que, por no reconocer la cita, hizo Rosell ("a quien sus rayos dio el Sol").

${ }_{25}$ Incluido también en Lope de Vega, Poesias liricas, ed. J. F. Montesinos, Madrid, 1925 (Clás. cast.), t. 2, pp. 218-222. En nota a la Primavera (pp. 256257), Montesinos recuerda muchas citas que atestiguan su gran difusión. 
${ }_{1188)^{26}}$. Parodiado en Loa Prado, p. 517a: "Bien podéis, Prado, empezar, / no lo dejéis de vergüenza"; sin embargo, el segundo verso era frase tan común, que podría ser independiente. Cf. El condenado por desconfiado (I, 13): "Salid, lágrimas, salid, / salid apriesa del pecho, / no lo dejéis de vergüenza", donde se ve una contaminación con la Égloga I de Garcilaso.

"Cansóse el Ñarro de Andújar, / que es aliñado en extremo" (Cáncer) ${ }^{27}$. Se canta la primera cuarteta de esta jácara en Los órganos y sacristanes (p. 636b).

"Cerca del Tajo en soledad amena" (Garcilaso, Égloga III). Citado como comienzo de narración en Don Gaiferos (p. $611 a)^{28}$.

"Compitiendo con las selvas / donde las flores madrugan" (Antonio de Mendoza) ${ }^{29}$. Parodiado en la Loa Prado (p. 517a): "Compitiendo con Romero, / donde el gran Roque madruga".

"Con los mejores de Asturias / sale de León Bernardo" (RG, 227; D, 649). Los dos primeros versos, sin alteración, en la Loa Fernán$\operatorname{dez}\left(\right.$ p. $\left.5^{60 a}\right)$.

"Cuando de Francia partimos / hicimos pleito homenaje" (RG, 257; D, 397). Los versos que cita Quiñones se habían hecho proverbiales y aparecen infinitas veces en obras literarias: "Con la mucha

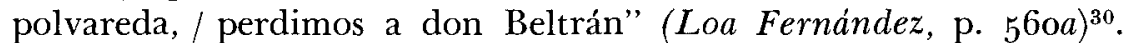

"Cuántos silbos, cuántas voces" (Góngora, ed. cit., t. 2, p. 122). Citado en la Loa Prado (p. $\left.5^{17} b\right)^{31}$.

${ }^{26}$ La primera cuarteta fue glosada por Lope en $E l$ peregrino en su patria (Obras sueltas, t. 5, Madrid, 1776, p. 114).

${ }^{27}$ Obras varias, ed. cit., fol. $67 \mathrm{r}^{\circ}$. Anónimo en Romances varios, p. 148 ; versiones manuscritas en Hill, op. cit., p. 173.

${ }^{28}$ Citado también en Quevedo, Entremés del Niño y Peralvillo de Madrid, Obras en verso, p. 534 b. Para la frecuencia de las citas de Garcilaso en el siglo xviI, véanse las notas de Rodríguez Marín a Lope de Vega, La gatomaquia, Madrid, 1935, pp. 121, 125, 185, 214, y a Cervantes, Viaje del Parnaso, Madrid, 1935, pp. 434-437.

${ }^{20}$ Obras poéticas, ed. R. Benítez Claros, Madrid, 1948, t. 1, p. 96. El romance se cita también en el auto de La vida es sueño (Calderón, Obras completas, t. 3, Madrid, 1952, p. $1398 b$ ).

${ }^{\text {so }}$ Cf. Menéndez Pidal, Flor nueva, pp. 106-108; Vélez de Guevara, El diablo cojuelo, ed. F. Rodríguez Marín, Madrid, 1941 (Clás. cast.), p. 136; Lope de Vega, La Dorotea, IV, 6, ed. E. S. Morby, Berkeley, 1958, pp. 367-968; Medina, $R H i$, 20 (1909), p. 247; LaGrone, op. cit., pp. 39-40. En el entremés de Barrionuevo El triunfo de los coches (impreso en 1617) se dice de un personaje llamado don Beltrán, enemigo de los coches: "Tiene muy mal gusto el señor don Beltrán, y debe de ser, sin duda, el que se perdió con la mucha polvoreda, y temiendo que se la han de hacer los coches, no los puede ver, porque no se la hagan segunda vez" (NBAE, t. 17, p. 211 $b$ ).

${ }^{31}$ Vuelto a lo divino por el propio Góngora (ed. cit., t. 2, p. 330). Otra curiosa alusión, con el mismo juego sobre la palabra "silbos", en el entremés de don Antonio de Mendoza, El examinador Miser Palomo (impreso en 1620): "No os canten cuantos silbos, cuantas voces" (NBAE, t. 17, p. 327a). 
"Dándose estaba Lucrecia / de las astas con Tarquino" (RG, 453; D, 1717$)^{32}$. Quiñones parodia este romance burlesco en cuatro lugares. En la Loa Prado, sólo dos versos: "Dándose estaba Juan Rana / de las astas con Treviño" (p. $\left.5^{1} 7^{b}\right)$. Con mayor extensión en $L a$ puente segoviana $I$ (p. $534 b)$ :

La ropa os dará los golpes, por que diga el romancillo:

"Dándose estaba la ropa de las astas con el río"... Decíales Manzanares:

"Pasito, mozas, pasito; que de mi agua las cerrajas tienen muy blando el pestillo",

y en La puente segoviana $I I$ (p. $538 b)$ :

La fuente os dará los golpes, por que diga el romancillo:

"Dándose estaba la fuente

de las astas con vos mismo"...

Decía la pobre zupia:

"Pasito, fuente, pasito, que soy agua de cerrajas sin blando o recio pestillo".

El entremés Pipote (cuyo texto es sumamente incorrecto) ofrece una tirada de 14 versos contrahechos sobre este romance (p. $718 a$ ):

Dándose estaba Pipote de las astas con el vino, potente rey de los tragos, gran vencedor de sí mismo... Deciale: "Plaza, hermano: pasito, señor, pasito, que de tal gusto las guardas tienen muy blando el pestillo, y ya sabrás mi casa, cantemos, pues se abrasa, se atragante su alteza, conquiste con tragos limpios $y$ no con furia los muros de su galillo".

s2 Se había impreso ya en 1593 en el Ramillete de flores, y volvía a estamparse todavía en 1655 en Romances varios (pp. 186-187), vida extraordinariamente larga para un romance de este tipo. Citan el comienzo la Mogiganga del rey D. Rodrigo... (ed. cit., p. 4) y los centones de disparates "Rebiente el mesmo demonio" y "Esse pardillo jayán" (Romances varios, pp. 375 y 138). 
"Despertad, hermosa Celia, / si por ventura dormís" (RG, 1248; D, 147o) ${ }^{33}$. La parodia, en Pistraco (p. 693b), reza:

Dispertad, zagal Pistraco,

si por ventura dormís, que quien desvela las mozas no es razón que duerma así.

“¡Diamante falso y fingido, / engastado en pedernal!” (RG, 760; D, 107). La Loa Prado cita el estribillo: "Porque, al fin, quien dice injurias / cerca está de perdonar" (p. $5^{17} b$ ).

“¿Dónde estás, señora mía, / que no te duele mi mal?” (RG, 8o; D, 1545). Citado en Los planetas (p. $\left.5^{61} b\right)^{34}$.

"En esta larga ausencia" (Lope de Vega, Poesias líricas, t. 2, p. 93). El último verso de la primera estrofa, "bien empleada, pero mal perdida", se parodia cuatro veces en los entremeses: "Yo soy quien soy, y saben qué es mi vida. / -Mal empleada, pero bien perdida" (Los alcaldes encontrados $V$, p. 675 ); "Ha sido esta comida / mal empleada, pero bien fingida" (El convidado, p. 806b); en La Verdad (p. 572b):

¿Adónde podré buscarte, Verdad, si ninguno te halla? -En los años, que allí está mal cubierta y bien negada;

y por fin: "Son muy de vuesastedes los antojos, / y éstos están ahora, aunque fingidos, / bien encajados, pero mal cumplidos" (La capeadora $I$, p. 550a). Quiñones debió de conocer esta canción por la música, ya que en la única versión impresa (Romancero general, $2^{\mathrm{a}}$. parte, Valladolid, 1605 ) falta la primera estrofa ${ }^{35}$.

"En un pastoral albergue, / que la guerra, entre unos robles"

s3 En Lope de Vega, El saber puede dañar (AcadN, t. 19, p. 6o8a); véase M. Goyri de Menéndez Pidal, "La Celia de Lope de Vega", NRFH, 4 (1950), pp. $363-364$.

${ }^{34}$ Estos dos versos proceden originalmente del romance juglaresco "De Mantua salió el marqués..." (WH, 165; D, 355); cf. la nota de F. Rodríguez MARín al Quijote, I, 5 (Nueva ed. crítica, Madrid, 1927, t. 1, pp. 183-184); LAGrone, op cit., p. 4o. Citado también en la Mogiganga del rey D. Rodrigo (ed. cit., p. 2) y en "Esse pardillo jayán" (Romances varios, p. 139), y parodiado en El condenado por desconfiado $(\mathrm{I}, 2)$ : “¿Dónde estáis, jamones míos, / que no os doléis de mi mal?"

${ }_{35}$ Para la bibliografía, atribución y difusión, véase Montesinos, Estudios, pp. 161, 258, 287-288 y 316; LAGrone, op. cit., pp. 36-37. La frase de La Dorotea $(\mathrm{V}, 4)$, "No fueran ellas mal empleadas si fueran bien agradecidas", parece estar más en relación con cierta poesía de Villamediana (Obras, Madrid, Diego Díaz de la Carrera, 1643, pp. 374-375), que empieza: "Servicios bien empleados, / aunque mal agradecidos, / tal sé yo que vais perdidos, / donde otros van ganados...", y acaba: "Mis servicios dedicados / a quien los haze perdidos, / pueden ser mal admitidos, / pero no mal empleados". 
(Góngora, ed. cit., t. 1, p. 224; D, 411). Con ligeros retoques sintácticos para ajustarlos a sus nuevos contextos, se emplean los versos tercero y cuarto del romance de Angélica y Medoro en la Loa Fernández (p. 56oa): "Me dejó por escondida, / o me perdonó por pobre", y en Los órganos y sacristanes (p. 698a): "Le dejó por escondido, / ni le perdonó por pobre"si.

"En un retrete, que apenas / se divisan las paredes" (RG, 1235; D, 969). En Los planetas (p. 562a: "divisen") y en Don Gaiferos (p. $612 b$ : "En mi retrete") $)^{37}$.

"Era del año la estación florida" (Góngora, Soledad I, ed. cit., t. 2, p. 53). El verso se recuerda en El avantal para empezar una narración (p. 645b): "Era de Julio la estación primera".

"Juramento llevan hecho / todos juntos a una voz" (RG, 237; D, 699). Citado en la Loa Prado (p. $5^{17 a}$ ).

"Mal segura zagaleja, / la de los lindos ojuelos" (Primavera y flor, ed. cit., p. 36; D, 1556: "pardos") ${ }^{38}$. Citado en Los planetas (p. $562 a)$.

"Malograda fuentecilla, / detén el curso y advierte" (D, 1368, de las Maravillas del Parnaso). Parodiado en la Loa Prado (p. 517a): "Mal formada compañía: / detén el curso y advierte"39.

"Manzanares, Manzanares, / arroyo aprendiz de río" (Quevedo, Obras en verso, p. 293; Romances varios, pp. 97-101). Citado en la Loa Prado (p. $5^{17}$ ).

"Oíd, señor don Gaiferos, / lo que como amigo os hablo" (RG, 104; D, 378) 4 $^{40}$ La Loa Prado cita el comienzo (p. 517b: "amiga", porque lo dice una mujer). Otro verso, que llegó a ser proverbial (Correas, Vocabulario, p. 234), en Los alcaldes encontrados IV (p. $674 b)$ : "Harto os he dicho; miraldo" y en la Loa seg. Figueroa p. 546b: "miredlo", deformación pedida por la asonancia).

${ }^{3 e}$ Cita este romance más extensamente el anónimo Baile del pastoral (NBAE, t. 18, p. $473^{a}$ ).

37 Otras citas en la Mogiganga del rey D. Rodrigo (ed. cit., p. 3) y en "Guardainfante era, y ya estoy" (Romances varios, p. 257).

${ }^{38}$ Villamediana, Obras, ed. cit., p. 411; también se ha atribuido a Antonio de Mendoza. A propósito de las atribuciones, véase la nota a la Primavera, pp. 245-246, donde se registran otras versiones y citas.

so El romance se menciona también en el anónimo Baile de la casa de amor (NBAE, t. 18, p. $475^{b}$ ), en la Vida de Estebanillo González, Madrid, 1934 (Clás. cast.), t. 2, p. 126, y en Enríquez Gómez, Vida de D. Gregorio Guadaña, cap. 7 (cf. Gallardo, Ensayo, t. 2, col. 4og).

"Atribuido a Miguel Sánchez "el divino" en el Mercurius de Patón (1621), y a Góngora en el Ramillete de flores (1593), en el Cancionero antequerano y en un ms. citado por Gallardo (la ed. de Foulché-Delbosc y la de Millé y Giménez rechazan la atribución). Cf. la nota de Rodríguez Marín al Quijote, II, 26 (Clás. cast., t. 5, pp. 50-52), y MEdiNa, RHi, 20 (1gog), p. 248. El anónimo Entremés de Melisendra (impreso en 1609) cita este y otros romances sobre el asunto ( $N B A E$, t. 17, pp. 105-111). 
“¿Para qué es, amor tirano, / tanta flecha y tanto arpón?”. "Los dos versos. .. son el principio de un romance del Conde de Villamediana", observa Cotarelo al anotar esta cita en la Loa Prado (p. $5^{17}$ a). En las Obras del Conde (ed. cit., p. 347) el segundo verso es "tanta flecha y tanto sol", y el "harpón" cierra la cuarteta: "tanta munición de rayos, / y tanto severo harpón”. La lección de Quiñones es la misma que la del centón de disparates "Estáuase la aldeana" (Romances varios, p. 363 ).

"Por las montañas de Jaca / furioso baja otra vez" (Flor de romances, Valencia, 1593, fol. $\left.137 \mathrm{v}^{0}\right)^{41}$. Citado en Los planetas (p. $562 a)$.

"Por muchos años y buenos / vengáis, Melisendra hermosa" (Don Gaiferos, p. 612b). Estos versos parecen estar en relación con los de Liñán de Riaza "Por muchos años y buenos / vuelvas, Belilla, a la plaza" (RG, 243; D, 1591; P. Liñán de Riaza, Rimas, Zaragoza, 1876 , p. 92). El primer verso aparece también en $\mathrm{D}, 1687$, y debe tal vez tenerse por frase hecha.

"Recuerde el alma dormida" (Jorge Manrique, Coplas, NBAE, t. 22, p. 228). Parodiado en El tiempo (p. $5^{08 b}$ ):

De la flaqueza en que he dado

saca fuerzas mi dolor,

$y$ es error,

pues confieso en lo cansado

que todo tiempo pasado

fue mejor.

"Rosas deshojadas vierte / a un valle que las recoge" (Francisco López de Zárate, Obras, Alcalá, María Fernández, 1651, p. 35) ${ }^{42}$. Se canta en Los órganos y sacristanes (p. 637b).

"Sale la estrella de Venus / al tiempo que el sol se pone" (RG, $5 ; \mathrm{D}, 33)^{43}$. Los dos primeros versos de este popularísimo romance se citan en Los planetas (p. $561 b$ ), y los cuatro primeros en Don Gaiferos (p. $612 b)$.

${ }^{41}$ Además, en los "Romancerillos de la Biblioteca Ambrosiana", RHi, 45 (1919), núm. 44, pp. 558-559, y en el "Romancero de la Biblioteca Brancacciana", $R H i, 65(1925)$, núm. 48 , pp. $3^{82-983}$. Con la variante "al través", en la Mogiganga del rey D. Rodrigo (ed. cit., p. 4), en el centón "Rebiente el mesmo demonio" (Romances varios, p. 377) y en las Rimas de Lupercio Leonardo de Argensola, ed. J. M. Blecua, Zaragoza, 1950, t. 1, p. 295 (en una nota, Blecua pone en duda la atribución).

${ }^{12}$ Anónimo en la Primavera y flor, ed. de 1641; cf. la reimpresión moderna, p. 231 , y la nota, p. 272.

${ }^{43}$ Para la atribución a Lope de Vega y la extraordinaria difusión de este romance, véase J. Millé Y Giménez, "Apuntes para una bibliografía de las obras no dramáticas atribuidas a Lope de Vega", RHi, 74 (1928), p. 460; MoNTEsinos, Estudios sobre Lope, p. 285 ; F. Rodríguez Marín, nota a Cervantes, Novelas ejemplares, ed. Clás. cast., t. 2, p. 113 . 
"Sentado en la seca yerba / que abrasó el rigor del hielo" (D, 1489 , de la Flor de romances). Quiñones adapta el estribillo del romance en Los mariones (p. 597a): "Ella me ha muerto, / que fui muy blando en el primer concierto" 44 .

"Sin color anda la niña / después que se fue su amante" (Primavera y flor, ed. cit., pp. 42 y 247 ; D, 1609). Hay un extenso comentario burlesco sobre este romance en El negrito hablador (pp. $605-606)^{45}$.

"Ya está guardado en la trena / tu querido Escarramán" (Quevedo, Obras en verso, p. 209; Romances varios, pp. 396-40o). Esta famosa jácara, recordada infinitas veces por los escritores de la época, se cita en Los planetas (p. 561 b: "metido"), se parodia en Don Gaiferos (p. 612b): "Ya está metido en Sansueña / tu querido Escarramán" (y un poco más adelante: "estos alfileres vivos / me prendieron sin pensar"), y se glosa burlescamente en El negrito hablador (p. $606 b)^{46}$.

"Zampuzado en un banasto / me tiene su Magestad" (Quevedo, Obras en verso, p. 223; Romances varios, p. 81). Parodiado en la Loa Prado: "Zampuzado en un banasto / nos tiene tu autoridad" (pp. $5^{16-5^{1}} 7$ ).

\section{Romances no IDENTIFICAdos}

No me ha sido posible todavía hallar los originales de las citas recogidas en esta sección.

“ ¡Al arma, comendadores! / Comendadores, ¡al arma!" (Los planetas, p. $5^{62 a}$ ).

"Aquí pagarás, Maestre, / lo presente y lo pasado" (Los planetas, p. $562 a$ ). Versos sacados tal vez de otra versión del romance de la muerte del Maestre de Santiago ("Yo me estaba allí en Coimbra", WH, 65; D, 966), donde se lee: "Aquí pagaréis, traidor, / lo de antaño y lo de hogaño"; o tal vez de uno del ciclo de don Álvaro de Luna

${ }^{44}$ De Lope de Vega, el cual atribuye el segundo verso del estribillo a Vicente Espinel (La Dorotea, IV, 1; V, 10; ed. cit., pp. 294 y 443). Cf. Montesinos, Estudios, pp. 241-243 y 320 .

${ }^{15}$ Con el título de El negro se publicó este entremés en la Segunda parte de las comedias de Tirso de Molina (1635). Aparece ahí (fol. $284 v^{\circ}$ ) esta curiosa variante:

$$
\begin{aligned}
& \text { lNÉs-"Sin color anda la niña" } \\
& \text { quiero que cantéis. } \\
& \text { Dom.- } \\
& \text { canten otra seguediya. }
\end{aligned}
$$

${ }^{46}$ La Mogiganga del rey D. Rodrigo (ed. cit., p. 7) también dice "metido". Para otras alusiones, véase la nota de Astrana Marín a Quevedo, Obras en verso, pp. 2o9-210; para el baile del Escarramán, la de Cotarelo (NBAE, t. 17 , pp. ccxliii-ccxliv). 
("Ya le sacan del Portillo"; D, 991, trae: "Aquí pagarás, Maestre, ( la tu grande villanía").

"Autor, el que llaman Prado, / ipluguiera a Dios no lo fueras!" (Loa Prado, p. $5^{16 b)}$.

"El mayor de los planetas / convidaba a las criaturas" (Los planetas, p. 562a; también Loa Prado, p. $517 a$ : "convida", errata de las eds. modernas $)^{47}$

"En peso la noche toda / sin cesar clamorearon" (Los planetas, p. 562a). En el Baile para el auto de la Nave se cantan estos versos, con dos más: "las campanas de Zamora / por muerte del rey Don Sancho" (NBAE, t. 17, p. cccii). El comienzo se cita también en el baile El mellado de Moreto.

"Ese pardillo jayán" (El barbero, pp. $\left.749^{-750}\right)^{48}$. Sigue:

que por el mundo campando, tantas marcas sujetó y mató tantos chulamos. Una noche que en la trena los corchetes le zamparon, hizo tanto estrago en ellos como en los moros Santiago.

Hay un centón de disparates que empieza "Esse pardillo jayán" (Romances varios, p. 132); lo que sigue es diferente.

"Hallarás quien bien te quiera, / mas no quien te quiera más" (Loa Prado, p. 517a). En Calderón, Amigo, amante y leal, I, 3: "Hallarás quien más te diga, / mas no quien te diga más" (Obras completas, t. 3, Madrid, 1956, p. $35^{\circ} b$ ).

"Levanta, fray Juan Garín, / que te hemos perdonado" (Loa Fernández, p. $561 a)$; "Levanta, fray Guarín, / que el viejo te ha perdonado" (Las patas de vaca, p. $745^{a}$ ). Se tratará de alguna versión de la leyenda del Monserrate. El episodio aludido se halla en Cristóbal de Virués, Historia de Monserrate, canto XIX (BAE, t. 17, p. $\left.5^{65}\right)$, pero referido con tales diferencias léxicas, que ésta no podría ser la fuente directa.

"¡Mil veces bien haya, amén, / árbol que tal fruto dio!” (Loa Prado, p. $\left.5^{17} b\right)$.

${ }^{47}$ El romance "El mayor de los planetas / convidaba las criaturas..." figura en el ms. 3890 de la B. N. M., fol. I $14 \mathbf{V}^{\circ}$; se encuentra vuelto a lo divino ("El criador de las $[s i c]$ planetas") entre las "Rimas del Incógnito" editadas por Foulchí-Delbosc, RHi, 37 (1916), p. 260.

${ }^{48}$ El barbero (de Entremeses nuevos, Alcalá, 1649) es una versión incorrecta, y probablemente pirateada, de El borracho, publicada dos años más tarde en las obras de Quiñones de Benavente (Iocoseria...). Este lugar nos ofrece un curioso ejemplo de texto viciado: donde El borracho trae una jácara escrita para la ocasión e íntimamente relacionada con la acción, El bar. bero pone otra jácara cualquiera. 
“...No es razón que se diga / que riñen marcas de bien / por cosas de niñería" (Jácara... Olmedo, p. $514 b$ ); "que no es justo que se diga / que riñen dioses de bien / por cosas de niñería" (Los planetas, p. $5^{62 a)}$.

“¿Quién como yo le ha tenido? / ¿Quién como yo le tendrá?” (Loa Prado, p. $5^{16 b}$ ). El ya mencionado romance "Guardainfante era, y ya estoy" (Romances varios, p. 257) dice: “¿Quién como yo la [por $l o$ ] ha tenido? / ¿Quién como yo la [por $l o]$ tendrá?"

"Reviente el mismo demonio, / muera el mismo Lucifer" (Los muertos vivos, p. 59oa). En los Romances varios (p. 375) hay un centón de disparates que empieza: "Rebiente el mesmo demonio, / muera Argel y viua España".

"Si las apeldó Marica, / sin decir oste ni moste" (Los órganos y sacristanes, p. 637a). En los Romances varios (pp. 25 1-256) hay una parodia que comienza igual.

"Tendré el invierno en Sevilla / y el veranito en Granada, / en Motril la caña dulce / y en Málaga la patata" (El invierno y el verano, p. $788 a$ ). Los primeros dos versos en El diablo cojuelo, tranco V (ed. cit., p. 92); en una comedia falsamente atribuida a Lope, Guerras de amor ${ }^{49}$ : "En Motril la caña dulce / cantaba siempre mi abuela", como si se tratara de una antigualla.

"Valentía en el donaire / y donaire en el hablar" (Loa Prado, p. $5^{16 b)}$. Con mirar en vez de hablar se halla en los centones "Esse pardillo jayán”, “Estáuase la aldeana” y "Rebiente el mesmo demonio" (Romances varios, pp. 137, 364 y 377); "Valentía en el donayre, / donayre en la valentía" en "Guardainfante era, y ya estoy" (ibid., pp. 256-257). Los anónimos Baile de Gallumba y Baile de Lela, Lela descritos por La Barrera (Catálogo, p. 624) empiezan: "Valentía en lo que pido / y donaire en el tomar". El Cancionero manuscrito de 1615 descrito por A. Rodríguez Moñino ( $N R F H$, 12, 1958, p. 19o) incluye un romance "Valentía de donayre".

"Ya, aguardando sus favores, / ninguna rama movéis" (Loa Prado, p. $\left.5^{17} b\right)$.

Hunter College, New York.

Hannah E. Bergman

49 AcadN, t. 6, p. 159a; véase la reseña de J. F. Montesinos, RFE, 17 (1930), p. 49 . 